\title{
Thoracic endovascular aortic repair: Evolution of therapy, patterns of use, and results in a 10-year experience
}

\author{
Nimesh D. Desai, MD, PhD, Alberto Pochettino, MD, Wilson Y. Szeto, MD, G. William Moser, MSN, \\ Patrick J. Moeller, BSc, Nishtha Sodhi, MD, Benjamin Jackson, MD, Edward Woo, MD, \\ Ronald M. Fairman, MD, and Joseph Bavaria, MD
}

\begin{abstract}
Objective: The introduction of aortic stent grafting in the treatment of thoracic aortic disease has pioneered unique treatment options and gained rapid clinical adoption despite a paucity of long-term outcome data. The purpose of this analysis is to examine all operations performed using thoracic aortic stent grafts at the University of Pennsylvania Health System.
\end{abstract}

\begin{abstract}
Methods: A total of 502 operations involving thoracic aortic stent grafting were performed between April 1999 and April 2009. Patients were followed in a prospectively collected clinical perioperative registry, and long-term outcomes were determined from administrative data sources. Aortic pathologies included aortic aneurysm, acute aortic dissection (types A and B), hybrid arch repairs, reinterventions with additional stents, pseudoaneurysm, chronic type B dissection, traumatic transection, penetrating aortic ulcer, and other unique indications.

Results: Patients' mean age at the time of thoracic endovascular aortic repair was $70.1 \pm 12.4$ years, and $51 \%$ of the patients were aged more than 70 years. Some $41 \%$ of patients were female, and the majority of patients $(87 \%)$ were hypertensive. Overall 30 -day mortality was $10.1 \%$. Multivariable risk factors for 30 -day mortality included urgent/emergency, Stanford type A aortic dissection, perioperative spinal ischemia, type $\mathrm{C}$ aortic coverage, hybrid arch operation, aortic transection, chronic renal failure, and age. Neurologic complications included permanent complete or incomplete paraplegia in 17 patients $(3.4 \%)$, reversible spinal cord ischemia in 26 patients $(5.1 \%)$, transient stroke in 16 patients $(3.2 \%)$, and permanent stroke in 23 patients $(4.6 \%)$. Greater extent of aortic coverage was not associated with risk of spinal cord ischemia. Access complications, stroke, and endoleaks diminished with increased operative experience over time. Risk factors for late mortality included urgent/emergency indications, hybrid procedures, traumatic aortic transection, age, perioperative paralysis, and chronic renal failure. Patients undergoing stent grafting for type B dissection were more likely to survive than patients undergoing stent grafting for aneurysms or other indications.
\end{abstract}

Conclusions: Thoracic aortic stent grafting has evolved to be a viable option to complement, augment, or even replace traditional treatments for aortic disease. These data illustrate the applicability of this evolving technology in the establishment of new treatment paradigms for complex aortic pathologies. (J Thorac Cardiovasc Surg 2011;142:587-94)

Thoracic endovascular aortic repair (TEVAR) has evolved during the past 15 years from hand-sewn experimental devices $^{1}$ to become the predominant technique for repair of most thoracic aortic pathology. We began the TEVAR program at the University of Pennsylvania in 1999, initially treating patients enrolled in pivotal trials with atherosclerotic aneurysms and occasional uses of stent grafts for other indications in dire emergencies. After the first TEVAR

\footnotetext{
From the Departments of Cardiovascular and Vascular Surgery, Hospital of the University of Pennsylvania, Philadelphia, Pa.

Disclosures: Authors have nothing to disclose with regard to commercial support.

Read at the 35th Annual Meeting of The Western Thoracic Surgical Association, Banff, Alberta, Canada, June 24-27, 2009.

Received for publication Aug 24, 2009; revisions received Jan 3, 2011; accepted for publication Feb 9, 2011; available ahead of print July 18, 2011.

Address for reprints: Nimesh D. Desai, MD, PhD, Hospital of the University of Pennsylvania, Cardiovascular Surgery, 3400 Spruce Street, 6th Floor Silverstein Pavil-

lion, Philadelphia, PA 19104 (E-mail: nimesh.desai@uphs.upenn.edu). 0022-5223/\$36.00

Copyright $(2) 2011$ Published by Elsevier Inc. on behalf of The American Association for Thoracic Surgery

doi:10.1016/j.jtcvs.2011.02.050
}

device approval in March 2005 (Gore TAG thoracic nitinol endograft; WL Gore \& Associates, Inc, Flagstaff, Ariz), we expanded our indications to include a variety of aortic pathologies, such as type B dissections, transections, hybrid arch replacement, and hybrid treatment of the proximal descending thoracic aorta in acute type A dissections. ${ }^{2} \mathrm{We}$ present our experiences with TEVAR over the past decade with an emphasis on comparing the differential impact of aortic pathologic diagnosis on early and late outcomes.

\section{MATERIALS AND METHODS \\ Surgical Technique}

TEVAR at the Hospital of the University of Pennsylvania is performed by a multidisciplinary team, including cardiovascular surgery, vascular surgery, cardiovascular anesthesia, neurology, and diagnostic radiology. The majority of cases were performed in a dedicated hybrid operating room able to accommodate fixed, high-quality, floor-mounted image intensifier transesophageal echocardiography equipment, intravascular ultrasound, neuromonitoring equipment, and a cardiopulmonary bypass pump if necessary, and multiple movable viewing screens that can simultaneously 


\author{
Abbreviations and Acronyms \\ $\mathrm{CI}=$ confidence interval \\ LSCA $=$ left subclavian artery \\ $\mathrm{OR}=$ odds ratio \\ TEVAR $=$ thoracic endovascular aortic repair
}

display angiography, hemodynamics, transesophageal echocardiography, and intravascular ultrasound. Our techniques of TEVAR for atherosclerotic aneurysms,${ }^{3}$ complicated Stanford type B dissections, ${ }^{4}$ hybrid arch procedures, ${ }^{5}$ and DeBakey I aortic dissections ${ }^{6}$ have been published. Briefly, all non-emergency patients undergo 3-dimensional reconstruction of contrast computed tomography scans (M2S, Inc, West Lebanon, NH) for preoperative case planning.

A fairly liberal approach to retroperitoneal access is used in cases of marginal femoral access, which generally occurred in vessels that were small, heavily circumferentially calcified, or extremely tortuous. Hybrid arch replacement cases were generally performed through a side-branch graft of the ascending aorta, ${ }^{5}$ and TEVAR during open repairs of DeBakey type I dissections was performed by deploying the stent just beyond the left subclavian artery (LSCA) origin under direct visualization of the distal arch. $^{6}$ TEVAR for complicated Stanford type B dissections was directed at sealing the primary intimal tear and reexpansion of the true lumen in the proximal descending thoracic aorta. ${ }^{4}$ Intravascular ultrasound was used to verify presence of the wire in the true lumen before advancement of stiff wires or the device. Ballooning is avoided in dissection cases. In general, we aim for $10 \%$ to $20 \%$ oversize at the proximal landing zone, which ideally is greater than $2 \mathrm{~cm}$ in length (particularly along the lesser curvature), has no thrombus, is not dissected, and has a consistent diameter. In instances of planned LSCA coverage, prophylactic left common carotid artery to LSCA bypass is performed perioperatively. Coiling of the LSCA from the ipsilateral brachial artery is routine in cases of left common carotid artery-LSCA bypass at the time of stent insertion.

\section{Neuroprotective Strategies}

Use of somatosensory evoked potential monitoring was not standardized in this population but evolved into a routine with increasing experience. Preoperative spinal drains were used in all patients who were considered high risk for spinal ischemia, including those with previous abdominal aortic aneurysm repair, descending thoracic aortic surgery, or planned complete aortic coverage from left subclavian to celiac axis (type $\mathrm{C}$ coverage). Descending thoracic aortic coverage is classified as type A, LSCA to midthoracic aorta (T6); type B, midthoracic aorta (T6) to celiac axis; and type $\mathrm{C}$, left subclavian to celiac axis. The protocol for management of spinal cord ischemia in the postoperative period included spinal drainage to cerebrospinal fluid pressure less than $10 \mathrm{cmH}_{2} \mathrm{O}$ and aggressive blood pressure augmentation with mean arterial pressures greater than $90 \mathrm{~mm} \mathrm{Hg}^{7}$

\section{Statistical Methods}

The University of Pennsylvania TEVAR Registry is a prospectively maintained perioperative database of thoracic aortic stent-graft procedures. The details of operative procedures are entered and verified by the attending surgeon. Outcomes are verified by the attending surgeon, and neurologic outcomes are verified by an attending neurologist with supportive imaging. Early outcomes were compared using standard univariate statistics, including the Student $t$ test for continuous data and Fisher exact test for categoric data. Multivariate analyses for predictors of operative mortality, stroke, and paraplegia were determined using logistic regression. All variables deemed clinically relevant were maintained in the model, and no automated selection procedures were used. Model discrimination was evaluated with the c-statistic, and model fit was evaluated with the Hosmer and Lemeshow goodness of fit test. Late survival was analyzed using the Kaplan-Meier survival technique, and multivariate predictors of late survival were determined using Cox proportional hazards modeling. Late survival data were determined using a linkage to the national Social Security Death Index. The institutional review board at the University of Pennsylvania approved the study and waived the need for patient consent.

\section{RESULTS}

\section{Patient Demographics and Operative Characteristics}

We performed 502 thoracic aortic stent grafting procedures from April 1999 to April 2009. Pathologic diagnosis leading to aortic stent grafting included thoracic aneurysms (64\%), complicated acute type B dissections (9.7\%), chronic type B dissections (2.4\%), penetrating atherosclerotic ulcers $(1.4 \%)$, pseudoaneurysms $(3.0 \%)$, arch hybrids $(5.2 \%)$, type A dissections $(9.5 \%)$, traumatic transections $(3.2 \%)$, TEVAR reoperations $(4.7 \%)$, and other indications including 2 ascending aortic stents $(1.2 \%)$.

Patient demographic characteristics are summarized in Table 1. Patients' mean age at the time of TEVAR was $70.1 \pm 12.4$ years, and $51 \%$ of patients were aged more than 70 years. Some $41 \%$ of patients were female, and the majority of patients $(87 \%)$ were hypertensive.

Stent grafts used included the Gore TAG (WL Gore \& Associates, Inc, Flagstaff, Ariz) (346/502, 69\%), Medtronic Talent (Medtronic Inc, Minneapolis, Minn) (87, 17\%), Medtronic Valiant (Medtronic Inc) (19, 3.4\%), Cook Zenith (Cook Medical, Inc, Bloomington, Ind) (35/ $502,7 \%)$, and others $(15 / 502,3.0 \%)$. Access locations included right femoral artery $(51 \%)$, left femoral artery $(17 \%)$, right common iliac artery $(12 \%)$, left common iliac artery $11 \%$, and others $(8 \%)$, including abdominal aorta, ascending aorta (hybrid procedures or type A dissection stents), and left ventricular apex. ${ }^{8}$ Aortic coverage included $40 \%$ type A (LSCA to T6), 23\% type B (midthoracic aorta to celiac axis), and $37 \%$ type $\mathrm{C}$ (left subclavian to celiac axis).

\section{Early Outcomes}

Perioperative outcomes are summarized in Table 2. Overall 30-day mortality was $10.1 \%$. Significant multivariable risk factors for 30-day mortality included urgent/emergency operation (odds ratio [OR], 4.9; confidence interval [CI], 2.2-11.2), type A dissection (OR, 3.4; CI, 1.1-10.9), perioperative spinal ischemia (OR, 4.8; CI, 2.1-11.1), type C aortic coverage (OR, 2.1; CI, 1.0-3.4), hybrid arch operation (OR, 2.7; CI, 1.0-9.0), aortic transection (OR, 10.3; CI, 2.3-25.5), chronic renal failure (OR, 6.2; $\mathrm{CI}, 2.7-14.9)$, and age (by year) (OR, 1.05; CI, 1.0-1.08) (Table 3).

Neurologic complications included permanent complete or incomplete paraplegia in 17 patients $(3.4 \%)$, reversible spinal cord ischemia in 26 patients $(5.1 \%)$, transient stroke in 16 patients $(3.2 \%)$, and permanent stroke in 23 
TABLE 1. Patient demographics

\begin{tabular}{|c|c|}
\hline Characteristic & No. $(\%)$ \\
\hline Age $($ mean $\pm \mathrm{SD})$ & $70.1 \pm 12.4 \mathrm{y}$ \\
\hline Age $>70$ y & $297(51 \%)$ \\
\hline Female sex & $208(41 \%)$ \\
\hline Diabetes & $90(18 \%)$ \\
\hline Hypertension & $436(87 \%)$ \\
\hline COPD & $109(27 \%)$ \\
\hline $\mathrm{CRF}$ & $50(10 \%)$ \\
\hline Smoking & $267(53 \%)$ \\
\hline Elective operation & $336(67 \%)$ \\
\hline Urgent operation & $60(12 \%)$ \\
\hline Emergency operation & $95(19 \%)$ \\
\hline Salvage operation & $10(2.0 \%)$ \\
\hline \multicolumn{2}{|l|}{ Type of procedure } \\
\hline - Atherosclerotic aneurysm & $323(64 \%)$ \\
\hline - Complicated type B dissection & $39(7.7 \%)$ \\
\hline - Chronic type B dissection & $30(6.0 \%)$ \\
\hline - Hybrid arch & $26(5.2 \%)$ \\
\hline - Transection & $16(3.2 \%)$ \\
\hline - Type A dissection + stent & $40(8.0 \%)$ \\
\hline - Penetrating ulcer & $7(1.4 \%)$ \\
\hline - Pseudoaneurysm & $15(3.0 \%)$ \\
\hline - Other & $6(1.2 \%)$ \\
\hline Early cohort & $251(50 \%)$ \\
\hline Late cohort & $251(50 \%)$ \\
\hline \multicolumn{2}{|l|}{ Aortic coverage: } \\
\hline - Type A coverage & $201(40 \%)$ \\
\hline - Type B coverage & $115(23 \%)$ \\
\hline - Type C coverage & $186(37 \%)$ \\
\hline LSCA bypass & $141(28 \%)$ \\
\hline Redo stent graft & $24(4.7 \%)$ \\
\hline Intraoperative spinal drain & $160(32 \%)$ \\
\hline
\end{tabular}

patients $(4.6 \%)$. Multivariable risk factors for perioperative permanent and transient stroke included hypertension (OR, 6.8; CI, 1.0-34), type A dissection (OR, 6.8; CI, 1.9-23), chronic renal failure (OR, 2.5; CI, 1.0-6.7), known cerebrovascular disease (OR, 4.5; CI, 1.8-11.1), and increased aortic (type C) coverage (OR, 2.6; CI, 11.2-6.0) (Table 4). Multivariable risk factors for perioperative permanent and transient paraplegia included complicated type B dissection (OR, 3.0; CI, 1.1-8.1), hybrid arch procedures (OR, 3.4; CI, 1.1-10.7), aortic transection (OR, 2.0; CI, 1.1-17.4), chronic renal failure (OR, 3.7; CI, 1.6-8.9), and smoking (OR, 2.8; CI, 1.2-6.5). Greater extent of aortic coverage was not associated with risk of spinal cord ischemia after adjustment for other factors (Table 5).

At the index procedure, 70 patients $(13.9 \%)$ had endoleaks, of which 35 were proximal and 18 were distal type I endoleaks, and 6 were type II endoleaks and 11 were type III interjunctional leaks. Of the 64 type I and III leaks,
TABLE 2. Perioperative outcomes

\begin{tabular}{|c|c|c|c|}
\hline Characteristic & $\begin{array}{c}\text { Stroke/TIA } \\
\text { n (\%) } \\
\end{array}$ & $\begin{array}{c}\text { Permanent } \\
\text { paraplegia } \\
\text { n }(\%) \\
\end{array}$ & $\begin{array}{c}\text { Early } \\
\text { mortality } \\
\text { n }(\%) \\
\end{array}$ \\
\hline All patients $(\mathrm{n}=502)$ & $39(7.8 \%)$ & $17(3.4 \%)$ & $50(10.1 \%)$ \\
\hline Age $>70$ y $(\mathrm{n}=297)$ & $26(8.8 \%)$ & $12(4.0 \%)$ & $35(11.8 \%)$ \\
\hline Female sex $(n=208)$ & $70(9.6 \%)$ & $6(2.9 \%)$ & $25(12.0 \%)$ \\
\hline Diabetes $(\mathrm{n}=90)$ & $7(7.8 \%)$ & $4(4.4 \%)$ & $10(11.1 \%)$ \\
\hline Hypertension $(\mathrm{n}=436)$ & $38(8.7 \%)$ & $15(3.4 \%)$ & $43(9.8 \%)$ \\
\hline $\operatorname{COPD}(\mathrm{n}=109)$ & $12(11.0 \%)$ & $6(5.5 \%)$ & $12(11.0 \%)$ \\
\hline $\operatorname{CRF}(\mathrm{n}=50)$ & $4(7.1 \%)$ & $9(18.0 \%)$ & $12(24 \%)$ \\
\hline Smoking $(\mathrm{n}=267)$ & $21(7.9 \%)$ & $12(4.5 \%)$ & $18(6.7 \%)$ \\
\hline Elective operation $(\mathrm{n}=336)$ & $23(6.9 \%)$ & $13(3.9 \%)$ & $21(6.3 \%)$ \\
\hline Urgent operation $(n=60)$ & $8(12.7 \%)$ & $1(1.8 \%)$ & $4(6.2 \%)$ \\
\hline Emergency operation $(\mathrm{n}=95)$ & $9(9.8 \%)$ & $2(2.2 \%)$ & $19(19.5 \%)$ \\
\hline Salvage operation $(\mathrm{n}=10)$ & $0(0 \%)$ & $1(10 \%)$ & $6(60 \%)$ \\
\hline \multicolumn{4}{|l|}{ Type of procedure } \\
\hline $\begin{array}{l}\text { - Atherosclerotic aneurysm } \\
\quad(\mathrm{n}=323)\end{array}$ & $21(6.8 \%)$ & $(3.1 \%)$ & $31(9.9 \%)$ \\
\hline $\begin{array}{r}\text { - Complicated type B } \\
\text { dissection }(\mathrm{n}=39)\end{array}$ & $2(5.1 \%)$ & $2(5.1 \%)$ & $3(7.7 \%)$ \\
\hline $\begin{array}{l}\text { - Chronic type B dissection } \\
\quad(\mathrm{n}=30)\end{array}$ & $2(6.6 \%)$ & $1(3.3 \%)$ & $2(6.6 \%)$ \\
\hline - Hybrid $\operatorname{arch}(\mathrm{n}=26)$ & $2(7.7 \%)$ & $3(11.5 \%)$ & $4(15.4 \%)$ \\
\hline - Transection $(\mathrm{n}=16)$ & $1(6.3 \%)$ & $1(6.3 \%)$ & $4(25 \%)$ \\
\hline $\begin{array}{l}\text { - Type A dissection }+ \text { stent } \\
\quad(\mathrm{n}=40)\end{array}$ & $6(15 \%)$ & $0(0 \%)$ & $6(15 \%)$ \\
\hline - Penetrating ulcer $(\mathrm{n}=7)$ & $1(14.2 \%)$ & $0(0 \%)$ & $0(0 \%)$ \\
\hline - Pseudoaneurysm ( $\mathrm{n}=15)$ & $3(20 \%)$ & $0(0 \%)$ & $0(0 \%)$ \\
\hline - Other $(n=6)$ & $0(0 \%)$ & $0(0 \%)$ & $0(0 \%)$ \\
\hline Early cohort $(\mathrm{n}=251)$ & $26(10.4 \%)$ & $9(3.6 \%)$ & $21(8.3 \%)$ \\
\hline Late cohort $(\mathrm{n}=251)$ & $14(5.6 \%)$ & $8(3.2 \%)$ & $28(11.4 \%)$ \\
\hline \multicolumn{4}{|l|}{ Aortic coverage } \\
\hline $\begin{array}{l}\text { - Type A coverage } \\
(\mathrm{n}=201)\end{array}$ & $9(4.1 \%)$ & $4(1.9 \%)$ & $16(7.8 \%)$ \\
\hline $\begin{array}{l}- \text { Type B coverage } \\
(\mathrm{n}=115)\end{array}$ & $5(4.6 \%)$ & $5(4.6 \%)$ & $11(9.2 \%)$ \\
\hline $\begin{array}{l}- \text { Type } \mathrm{C} \text { coverage } \\
(\mathrm{n}=186)\end{array}$ & $21(11.4 \%)$ & $7(3.5 \%)$ & $24(12.8 \%)$ \\
\hline LSCA coverage $(\mathrm{n}=141)$ & $11(7.6 \%)$ & $4(3.1 \%)$ & $13(9.0 \%)$ \\
\hline No LSCA coverage $(\mathrm{n}=361)$ & $36(10.1 \%)$ & $14(4.0 \%)$ & $35(9.7 \%)$ \\
\hline Redo stent graft $(\mathrm{n}=24)$ & $3(12.5 \%)$ & $0(0 \%)$ & $1(4.2 \%)$ \\
\hline $\begin{array}{l}\text { Intraoperative spinal drain } \\
\qquad(\mathrm{n}=160)\end{array}$ & $11(7.0 \%)$ & $8(5.0 \%)$ & $14(8.8 \%)$ \\
\hline
\end{tabular}
$(\mathrm{n}=160)$

COPD, Chronic obstructive pulmonary disease; $C R F$, chronic renal failure; $T I A$, transient ischemic attack.

$43(67 \%)$ were resolved at the index procedure with additional ballooning or placement of another stent graft.

To delineate the effect of greater operative experience with TEVAR on outcomes, we compared the outcomes of the first 251 patients undergoing TEVAR (early cohort) with the more recent 251 patients (late cohort). Overall, the late cohort was older; more likely to undergo emergency procedures, type A dissections, and transections; and more likely to have chronic renal failure and to be smokers. Despite this, as outlined in Figure 1, access 
TABLE 3. Multivariate predictors of operative mortality using logistic regression

\begin{tabular}{|c|c|c|c|}
\hline & Odds Ratio & $\mathbf{9 5} \% \mathbf{C I}$ & $P$ value \\
\hline Age & 1.05 & $1.01-1.08$ & .01 \\
\hline Female sex & 1.5 & $0.75-2.8$ & .26 \\
\hline Diabetes & 1.1 & $0.48-2.5$ & .82 \\
\hline Hypertension & 0.8 & $0.3-3.7$ & .64 \\
\hline COPD & 1.7 & $0.78-3.7$ & .18 \\
\hline $\mathrm{CRF}$ & 6.2 & $2.7-14.9$ & .0001 \\
\hline Smoking & 0.79 & $0.6-01.1$ & .35 \\
\hline \multicolumn{4}{|c|}{ Type of procedure (vs aneurysm) } \\
\hline $\begin{array}{l}\text { - Complicated type B } \\
\text { dissection }\end{array}$ & 0.86 & $0.27-2.7$ & .8 \\
\hline - Hybrid arch & 2.7 & $1.1-9.0$ & .03 \\
\hline - Transection & 10.3 & $2.3-25.5$ & .002 \\
\hline - Type A dissection & 3.4 & $1.1-10.9$ & .03 \\
\hline Later cohort & 1.4 & $0.7-2.9$ & .3 \\
\hline Redo stent graft & 1.2 & $0.3-4.8$ & .7 \\
\hline Type $\mathrm{C}$ coverage & 2.3 & $1.0-3.4$ & .05 \\
\hline $\begin{array}{l}\text { Perioperative paralysis/ } \\
\text { paraparesis }\end{array}$ & 4.8 & $2.1-11.1$ & .004 \\
\hline Urgent/emergency & 4.9 & $2.2-11.2$ & .001 \\
\hline
\end{tabular}

complications, endoleak, and incidence of perioperative stroke were reduced in the late cohort. Mortality and paraplegia rates were similar in both cohorts despite increasing complexity.

TABLE 4. Multivariate predictors of perioperative stroke (permanent and transient)

\begin{tabular}{|c|c|c|c|}
\hline & Odds Ratio & $95 \%$ CI & $P$ value \\
\hline Age (decile) & 1.02 & $0.98-1.06$ & .2 \\
\hline Female sex & 1.4 & $0.7-3.0$ & .3 \\
\hline Diabetes & 1.1 & $0.4-2.6$ & .9 \\
\hline Hypertension & 6.8 & $1.0-34$ & .05 \\
\hline COPD & 1.9 & $0.8-4.3$ & .12 \\
\hline $\mathrm{CRF}$ & 2.5 & $0.94-6.7$ & .05 \\
\hline Smoking & 0.8 & $0.4-1.9$ & .7 \\
\hline \multicolumn{4}{|c|}{ Type of procedure (vs aneurysm) } \\
\hline $\begin{array}{l}\text { 1. Complicated type B } \\
\text { dissection }\end{array}$ & 0.8 & $0.2-2.7$ & .7 \\
\hline 2. Hybrid arch & 1.5 & $0.3-7.4$ & 6 \\
\hline 3. Transection & 4.7 & $0.5-33$ & .18 \\
\hline 4. Type A dissection & 6.8 & $1.9-23$ & .002 \\
\hline Later cohort & 0.43 & $0.2-0.95$ & .04 \\
\hline $\begin{array}{l}\text { History of cerebrovascular } \\
\text { disease }\end{array}$ & 4.5 & $1.8-11.1$ & .009 \\
\hline Type $\mathrm{C}$ coverage & 2.6 & $0.8-4.9$ & .029 \\
\hline Urgent/emergency & 1.7 & $0.7-4.3$ & .2 \\
\hline
\end{tabular}

$C O P D$, Chronic obstructive pulmonary disease; $C R F$, chronic renal failure. HosmerLemeshow goodness of fit $\chi 2=7.7, P=.4, \mathrm{C}$-statistic $=0.77$. Cohort (early vs late) comparison of first 251 cases with second 251 cases using the earlier cohort as the reference value. Type $\mathrm{C}$ coverage is coverage of the entire thoracic aorta from the left subclavian artery orifice to the celiac artery.
TABLE 5. Multivariate predictors of perioperative paraplegia (permanent and transient)

\begin{tabular}{lccc}
\hline & Odds Ratio & $\mathbf{9 5} \%$ CI & $\boldsymbol{P}$ value \\
\hline Age & 1.01 & $0.97-1.1$ & .6 \\
Female sex & 1.6 & $0.8-3.3$ & .14 \\
Diabetes & 0.78 & $0.3-1.9$ & .6 \\
Hypertension & 0.8 & $0.2-2.2$ & .6 \\
COPD & 1.4 & $0.7-3.1$ & .3 \\
CRF & 3.7 & $1.6-8.9$ & .002 \\
Smoking & 2.8 & $1.2-6.5$ & .01 \\
Type of procedure (vs atherosclerotic aneurysm) & & \\
$\quad$ 1. Complicated type B & 3.0 & $1.1-8.1$ & .02 \\
$\quad$ dissection & & & \\
2. Hybrid arch & 3.4 & $1.1-10.7$ & .03 \\
3. Transection & 2.0 & $1.1-17.4$ & .04 \\
$\quad$ 4. Type A dissection & 1.2 & $0.3-5.2$ & .7 \\
Later cohort & 1.3 & $0.6-2.7$ & .4 \\
Urgent/emergency & 0.8 & $0.4-2.0$ & .7 \\
Type C coverage (vs type A & 1.1 & $0.5-2.6$ & .7 \\
$\quad$ coverage) & & & \\
Type B coverage (vs type A & 1.5 & $0.6-3.7$ & .4
\end{tabular}

coverage)

$C O P D$, Chronic obstructive pulmonary disease; $C R F$, chronic renal failure. HosmerLemeshow goodness of fit $\chi 2=4.6, P=.08, C$-statistic $=0.73$. Cohort (early vs late) comparison of first 251 cases with second 251 cases using the earlier cohort as the reference value. Type $\mathrm{C}$ coverage is coverage of the entire thoracic aorta from the left subclavian artery orifice to the celiac artery.

\section{Late Mortality}

Overall survival was $51 \%$ at 9.8 years. The median follow-up period was 25.3 months (interquartile range, 9.8-41.7 months), providing 1171 patient-years of followup. As illustrated in Figure 2, patients undergoing TEVAR for type B dissection were more likely to survive than those undergoing TEVAR for aneurysms or all other indications. Risk factors for late mortality determined by Cox proportional hazards modeling included urgent/emergency index operation (OR, 2.7; CI, 1.8-4.1), hybrid procedures (OR, 2.1; CI, 1.1-4.2), aortic transection (OR, 3.6; CI, 1.1-9.1), age (years) (OR, 1.05; CI, 1.03-1.07), perioperative paralysis (OR, 1.5; CI, 1.0-2.3), and chronic renal failure (OR, 2.4; CI, 1.4-4.1). Patients undergoing stent grafting for type $\mathrm{B}$ dissection were more likely to survive (OR, 0.6; CI, 0.3-0.98) than patients undergoing stent grafting for aneurysms or other indications. Residual endoleak was not associated with late mortality (OR, 1.1; CI, 0.5-2.5) (Table 6).

\section{DISCUSSION}

Traditional open repair of the thoracic aorta is associated with significant morbidity and mortality. Since the use of the first homemade thoracic aortic stent graft at Stanford University in $1992,{ }^{1}$ stent-graft technology has evolved with multiple manufacturers, smaller, more flexible delivery systems, improved device conformability, less porosity, and a greater variety of sizing options. ${ }^{9}$ Evolution of the 


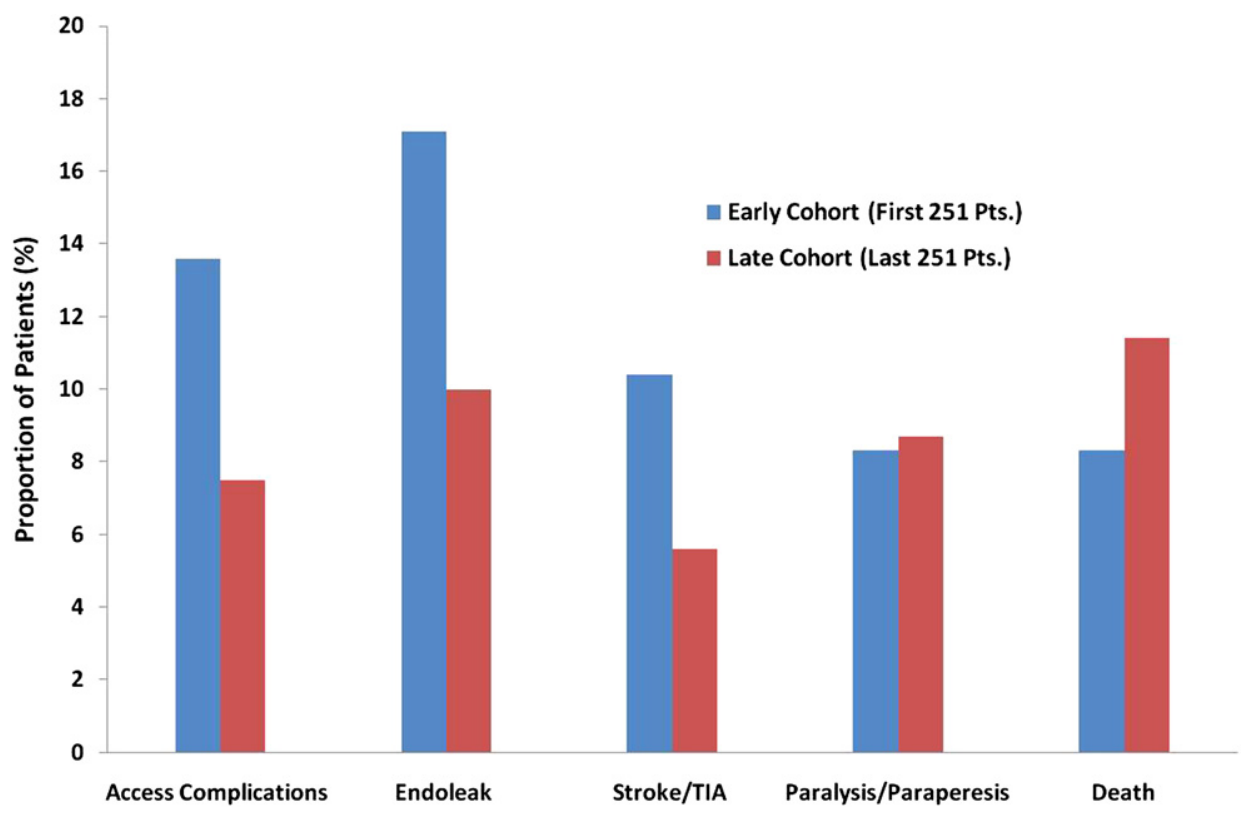

FIGURE 1. Perioperative outcomes stratified according to early (first 251 patients) or late (last 251 patients) cohort.

multidisciplinary TEVAR team to include cardiac and vascular surgeons, cardiovascular anesthesia, diagnostic radiology, and neurologists has enabled application of this technology to sicker patients while maintaining outcomes.

The current study has demonstrated the outcomes of "real-world" use of TEVAR from the University of Pennsylvania TEVAR Registry. Our principle finding in this report is that variability of outcomes for TEVAR is highly dependent on the initial indication for operation. We found that operative mortality was higher in patients undergoing TEVAR for hybrid arch replacement, traumatic transection, and acute Stanford type A dissection, findings that are not surprising given the higher acuity and anatomic complexity in these patients. Hybrid arch replacement and traumatic transection repair were also more likely to be associated with perioperative paraplegia. In the longer term, patients with TEVAR for type B dissection complicated by limb or visceral malperfusion, refractory hypertension or pain, or rupture or impending rupture had improved survival compared with patients with aneurysmal or other indications.

In the literature, results of endovascular treatment of malperfusion with thoracic aortic stent grafts have been highly favorable compared with open surgery, and endovascular repair is now the treatment of choice for these extremely high-risk and complex patients. ${ }^{5,10-12}$ TEVAR, in combination with other endovascular interventions, can successfully seal the entry tear, thrombose the thoracic

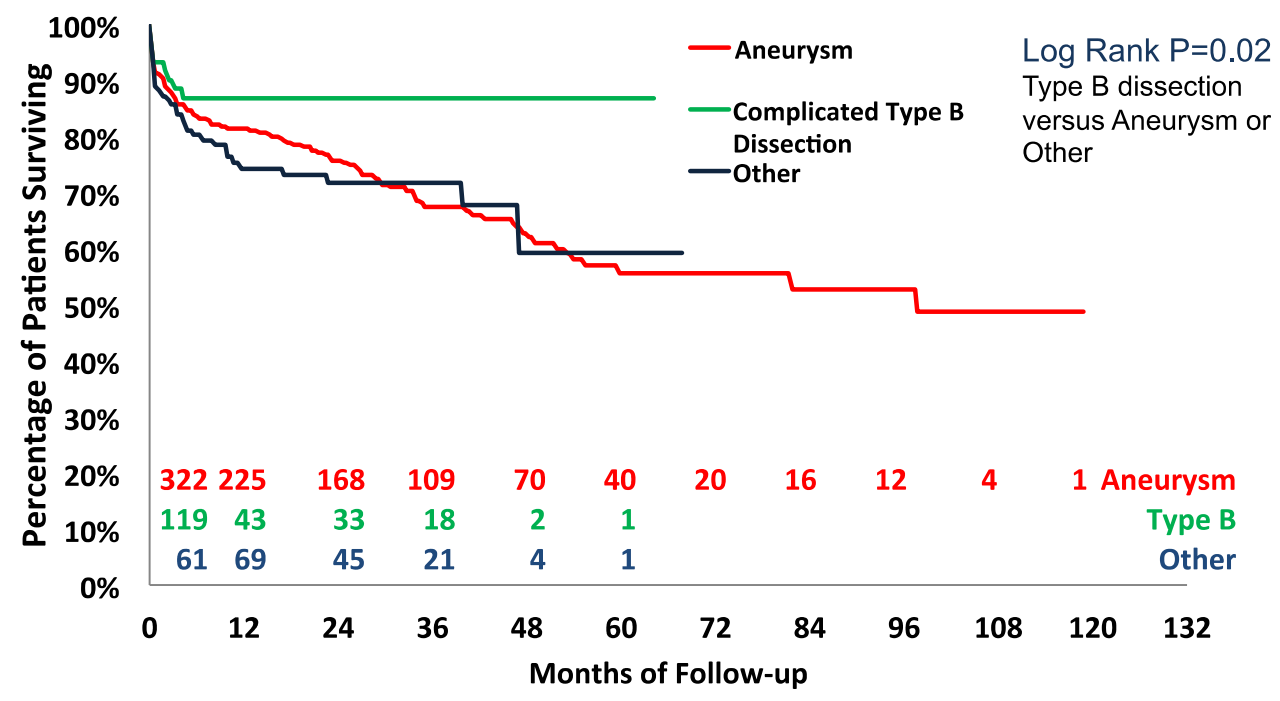

FIGURE 2. Long-term survival stratified by indication for TEVAR. 
TABLE 6. Multivariate predictors of long-term survival using Cox proportional hazards regression

\begin{tabular}{lcc}
\hline & Hazard Ratio & $\mathbf{9 5 \%}$ CI \\
\hline Age & 1.05 & $1.03-1.07$ \\
Female sex & 1.1 & $0.8-1.6$ \\
Diabetes & 1.1 & $0.7-1.7$ \\
Hypertension & 1.1 & $0.6-1.9$ \\
COPD & 1.3 & $0.88-1.98$ \\
CRF & 2.4 & $1.4-4.1$ \\
Smoking & 0.98 & $0.7-1.4$ \\
Type of procedure (vs aneurysm) & & \\
$\quad$ 1. Complicated type B & 0.6 & $0.3-0.98$ \\
$\quad$ dissection & & \\
$\quad$ 2. Hybrid arch & 2.1 & $1.1-4.2$ \\
$\quad$ 3. Transection & 3.5 & $1.3-9.3$ \\
$\quad$ 4. Type A dissection & 1.4 & $0.6-2.9$ \\
Paralysis & 1.5 & $1.0-2.3$ \\
Type C coverage & 1.0 & $0.7-1.7$ \\
Residual endoleak & 1.1 & $0.5-2.5$ \\
Urgent/emergency operation & 2.7 & $1.8-4.1$ \\
\hline
\end{tabular}

COPD, Chronic obstructive pulmonary disease; $C R F$, chronic renal failure. Cohort (early vs late) comparison of first 251 cases with second 251 cases using the earlier cohort as the reference value. Type $\mathrm{C}$ coverage is coverage of the entire thoracic aorta from the left subclavian artery orifice to the celiac artery.

portion of the false lumen, and relieve malperfusion syndromes. ${ }^{10}$ Longer-term follow-up has shown favorable remodeling of the aorta in acute type B dissection patients treated with TEVAR, which has prompted interest in using TEVAR for treatment of uncomplicated cases to prevent the 5- to $15-\mathrm{mm} /$ year aortic dilatation growth rate observed in medically treated cases. ${ }^{13}$ Although we have not used TEVAR for asymptomatic acute type B dissections to date, clinical trials to assess TEVAR for this indication are currently under way.

Our group, along with others, has also been proactive to explore the use of TEVAR in emerging indications, including hybrid arch repair in very high-risk patients undergoing open arch repair ${ }^{14,15}$ and to deploy a stent graft in the proximal descending thoracic aorta at the time of open DeBakey type I acute aortic dissection repair. ${ }^{6,16}$ We do this to fully reexpand the true lumen/thrombose the false lumen in the thoracic aorta and exclude the portion of the aorta that is most likely to dilate in longer-term followup. ${ }^{17}$ We have shown that this method may limit further dilatation of the proximal descending thoracic aorta. Our experience with hybrid arch replacement has been somewhat mixed, with improved results in exceedingly highrisk elderly patients but little benefit to this approach in younger patients. ${ }^{14}$

The significant impact of chronic renal failure on early and late death, stroke, and paraplegia was striking and has led to a reevaluation of use of this treatment in this subset of patients if they are asymptomatic. As discussed by Svensson and colleagues ${ }^{18}$ in the 2007 Expert Consensus Document on the Treatment of Descending Thoracic Aortic
Disease Using Endovascular Stent-Grafts, use of TEVAR in patients in whom the anticipated longer-term outcomes are exceedingly poor may only prevent aneurysm-related death but not prevent death from other causes. We now tend to avoid TEVAR in patients who are otherwise higher risk with concomitant chronic renal failure. The elevated risk in patients with chronic renal failure is likely a result of aggravation of poor renal function from intravenous contrast loads, hemodynamic shifts, and the severe microvascular disease found in these patients. In previous work by our group, serum creatinine greater than 2.0 was associated with elevated risks of major adverse events after TEVAR. ${ }^{19}$

In our analysis, we noted a significant learning curve with respect to clinical outcomes. By comparing our first 251 patients with our last 251 patients, we observed fewer access complications, strokes, and endoleaks in the latter cohort. With regard to access complications, after initial experiences with inability to advance the device or arterial trauma from the device, we adopted a strategy of defaulting to retroperitoneal iliac exposure for access with or without sewing a conduit. In our early experience with TEVAR for severely atherosclerotic aneurysms, we found a prohibitive stroke risk in patients with grade IV atheroma in the arch and no longer offer TEVAR to these patients. ${ }^{7} \mathrm{We}$ also became more aggressive managing endoleaks, particularly type 1 endoleaks, with placement of additional cuffs or ballooning at the index procedure to ensure a good seal. ${ }^{20}$

\section{CONCLUSIONS}

The outcomes of TEVAR are variable and dependent on the nature of the initial aortic pathology. Our experiences over the past 10 years have led to systematic improvements in our outcomes despite offering this therapy to a wider variety of patients with varying operative indications. Stentgraft design, surgical technique, and perioperative medical care continue to evolve, but surgeons must maintain a vigilant approach to prospective investigations and long-term follow-up to ensure optimum patient outcomes with this technology.

\section{References}

1. Dake MD, Miller DC, Semba CP, Mitchell RS, Walker PJ, Liddell RP. Transluminal placement of endovascular stent-grafts for the treatment of descending thoracic aortic aneurysms. $N$ Engl J Med. 1994;331:1729-34.

2. Milner R, Bavaria JE, Baum RA, Carpenter JP, Velazquez OC, Brinster D, et al. Thoracic aortic stent grafts. Semin Roentgenol. 2001;36:340-50.

3. Bavaria JE, Appoo JJ, Makaroun MS, Verter J, Yu ZF, Mitchell RS, Gore TAG Investigators. Endovascular stent grafting versus open surgical repair of descending thoracic aortic aneurysms in low-risk patients: a multicenter comparative trial. J Thorac Cardiovasc Surg. 2007;133:369-77.

4. Szeto WY, McGarvey M, Pochettino A, Moser GW, Hoboken A, Cornelius K, et al. Results of a new surgical paradigm: endovascular repair for acute complicated type B aortic dissection. Ann Thorac Surg. 2008;86:87-93.

5. Szeto WY, Bavaria JE, Bowen FW, Woo EY, Fairman RM, Pochettino A. The hybrid total arch repair: brachiocephalic bypass and concomitant endovascular aortic arch stent graft placement. J Card Surg. 2007;22:97-104.

6. Pochettino A, Brinkman WT, Moeller P, Szeto WY, Moser GW, Cornelius K, et al. Antegrade thoracic stent grafting during repair of acute DeBakey I 
dissection prevents development of thoracoabdominal aortic aneurysms. Ann Thorac Surg. 2009;88:482-90.

7. Cheung AT, Weiss SJ, McGarvey ML, Stecker MM, Hogan MS, Escherich A, et al. Interventions for reversing delayed-onset postoperative paraplegia after thoracic aortic reconstruction. Ann Thorac Surg. 2002;74:413-21.

8. Szeto WY, Moser WG, Desai ND, Milewski RK, Cheung AT, Pochettino A, et al. Transapical deployment of endovascular thoracic aortic stent graft for an ascending aortic pseudoaneurysm. Ann Thorac Surg. 2010;89:616-8.

9. Appoo JJ, Moser WG, Fairman RM, Cornelius KF, Pochettino A, Woo EY, et al. Thoracic aortic stent grafting: improving results with newer generation investigational devices. J Thorac Cardiovasc Surg. 2006;131:1087-94.

10. Fattori R, Tsai TT, Myrmel T, Evangelista A, Cooper JV, Trimarchi S, et al. Complicated acute type B dissection: is surgery still the best option?: a report from the International Registry of Acute Aortic Dissection. JACC Cardiovasc Interv. 2008;1:395-402.

11. Dake MD, Kato N, Mitchell RS, Semba CP, Razavi MK, Shimono T, et al. Endovascular stent-graft placement for the treatment of acute aortic dissection. $N$ Engl J Med. 1999;340:1546-52.

12. Nienaber CA, Fattori R, Lund G, Dieckmann C, Wolf W, von Kodolitsch Y, et al. Nonsurgical reconstruction of thoracic aortic dissection by stent-graft placement. N Engl J Med. 1999;340:1539-45.

13. Blount KJ, Hagspiel KD. Aortic diameter, true lumen, and false lumen growth rates in chronic type B aortic dissection. AJR Am J Roentgenol. 2009;192: W222-9.

14. Milewski RK, Szeto WY, Pochettino A, Moser GW, Moeller P, Bavaria JE. Have hybrid procedures replaced open aortic arch reconstruction in high risk patients: a comparative study of open arch debranching with endovascular stent graft placement and conventional open total and distal aortic arch reconstruction. $J$ Thorac Cardiovasc Surg. 2010;140:590-7.

15. Czerny M, Gottardi R, Zimpfer D, Schoder M, Grabenwoger M, Lammer J, et al. Mid-term results of supraaortic transpositions for extended endovascular repair of aortic arch pathologies. Eur J Cardiothorac Surg. 2007;31:623-7.

16. Jakob H, Tsagakis K, Tossios P, Massoudy P, Thielmann M, Buck T, et al. Combining classic surgery with descending stent grafting for acute DeBakey type I dissection. Ann Thorac Surg. 2008;86:95-101

17. Park KH, Lim C, Choi JH, Chung E, Choi SI, Chun EJ, et al. Midterm change of descending aortic false lumen after repair of acute type I dissection. Ann Thorac Surg. 2009;87:103-8.

18. Svensson LG, Kouchoukos NT, Miller DC, Bavaria JE, Coselli JS, Curi MA, et al., Society of Thoracic Surgeons Endovascular Surgery Task Force. Expert consensus document on the treatment of descending thoracic aortic disease using endovascular stent-grafts. Ann Thorac Surg. 2008;85(1 Suppl):S1-41.

19. Wang GJ, Fairman RM, Jackson BM, Szeto WY, Pochettino A, Woo EY. The outcome of thoracic endovascular aortic repair (TEVAR) in patients with renal insufficiency. J Vasc Surg. 2009;49:42-6.

20. Parmer SS, Carpenter JP, Stavropoulos SW, Fairman RM, Pochettino A, Woo EY, et al. Endoleaks after endovascular repair of thoracic aortic aneurysms. $J$ Vasc Surg. 2006;44:447-52.

\section{Discussion}

Dr Craig Miller (Stanford, Calif). For those of you who don't know, Nimesh Desai is a Canadian surgeon who went across the border to Philadelphia for advanced cardiovascular surgical training. He is going to join the staff at Penn in July. This was a nice presentation with a lot of information, which has generated in my mind a lot of questions. I think you are Eastern Canadian, right? Ontario?

Dr Desai. Yes.

Dr Miller. First, especially with respect to those survival curves, your numbers are fairly robust out to 3 to 4 years, but I wish you would have amputated everything beyond that time because you just don't have enough patients remaining at risk to support meaningful inferences. The median follow-up was 25 months, so this is really a short-term follow-up study, albeit still valuable. That is a word of caution.
Number two, it is a heterogeneous substrate that has both strengths and weaknesses. Most would say that is a weakness, and you may be comparing apples with prunes with tomatoes. Conversely, I think there are some strengths to be derived from this heterogeneous substrate. Number one, the most compelling good news here is something we hoped for in October 1996 when Michael Dake and I did our first thoracic aortic stent graft for acute complicated type B dissection (our early experience was subsequently published in 1999, or 10 years ago): Thoracic aortic stent grafts are going to save more lives in the very sick patients with acute complicated type B dissection than they are in any of the other pathologic subsets. That goes against traditional thinking, but I think your data have demonstrated this clearly. Although none of the clinically available stent grafts in the United States are approved by the Food and Drug Administration for this indication (it is all off-label), this application is probably where TEVAR is going to prove to be the most life-saving. It is also a topic that has never been tested in a randomized clinical trial. Patients with acute ( $<14$ days) type $B$ dissection are now being randomized in Germany and Scandinavia in the ADSORB trial comparing TEVAR with best medical therapy, but patients with complicated acute type B are excluded, so there is more to be learned.

Now, what about the negatives of the heterogeneous substrate? For example, for your hybrid arch cases, the results aren't pretty. On the basis of your analysis, where should you change your practice and abandon or give up stent grafting? Your results are not unique because all hybrid thoracoabdominal and hybrid arch TEVAR results are poor, and this hybrid approach is rapidly being abandoned by most authorities. How can we get these patients to a center that can reproducibly perform a relatively safe and durable open surgical arch or open thoracoabdominal repair? There are many hospitals in the United States where the thought of putting a patient on the pump and cooling them down for profound hypothermic circulatory arrest for total arch or thoracoabdominal aortic replacement is analogous to being sent to the gas chamber in San Quentin prison. Of course this is not true in other centers that have special expertise and are very experienced. The advocates for continuing hybrid arch procedures just don't get this point, and in their hands they can't do open repairs with reasonably low risk. How do we get the patients away from centers like that, or will they continue what you have tried where it doesn't work very well? Or, alternatively, where should we say that doing nothing is the most prudent option for these very old and high risk patients? At Stanford we continue to stand by our statement 5 years ago that asymptomatic patients who are judged inoperable for open aortic graft replacement because of multiple other medical problems should not be offered TEVAR because treatment will not improve quality of life and their 5-year life expectancy is dismal secondary to the other comorbidities.

Dr Desai. I want to thank Dr Miller for his comments. He has been a thought leader in our field of aortic surgery and cardiac surgery in general for a long time.

With regard to hybrid procedures, as Dr Kariyana Milewski presented from our group at the American Association of Thoracic Surgery this year, we don't see a benefit in doing hybrid procedures for arch surgery in what I would still call higher risk but younger patients, those aged less than 70 years. Our data showed that in patients aged more than 70 years who are also high risk for other reasons, 
there may be a potential role for offering them a hybrid solution, although we don't really know what their long-term survival would be without any procedure at all. This brings up another point, which is when we compare all of this technology with itself, using different indications, or other open operations, we have overlooked the biggest control group, which is the medically treated group. Our approach in terms of offering hybrid arch operations today is in the person who is prohibitively high risk only. It is our experience that it is not an ideal solution in a younger patient, even though it may be a "less invasive" or a more convenient operation, particularly for practitioners who are not trained to use circulatory arrest.

Dr Miller. You described 2 other substrates where the results are not so good, probably because the patients are sicker. That is one thing that has changed over the last 10 years: You are pushing the envelope, taking on cases today you wouldn't have even dreamed about stent grafting 10 years ago. One of these subsets is acute traumatic aortic transection. You only had 16 in this series, and the results were not good in terms of paraplegia, early death, and late death. I assume they all had TEVAR because you were forced to do something (eg, rupture or other life-threatening major complication). If these patients have multiple other injuries and no life-threatening emergency complication related to the aorta, we need to remember there remains a role for expectant negative inotropic, controlled hypotension management followed by elective open surgical graft replacement weeks or even months later. Have you backed off emergency TEVAR for your acute aortic tear cases? Believe it or not, not every patient has to be treated with an emergency stent graft, a practice that unfortunately is becoming popular around the world. The long-term durability of TEVAR in these patients who generally are very young is dubious at best. If you don't have a life-threatening emergency right under your nose, what about treating them medically, stabilizing them, get them to where you can do a more definitive and durable open operation with minimal risk?

Dr Desai. In younger patients, that is our preferred approach, to stabilize them medically and perform an open operation when it is appropriate. It is only in the truly emergency salvage case that we have been performing TEVAR for a transaction.

Dr Miller. Those are wise words, which I hope all the audience heard.

Next, when you threw a stent graft into the downstream thoracic aorta like a frozen elephant trunk in the patients with acute type A dissection, it also did not work out very well. Has your enthusiasm for this at the time of open ascending and total arch surgical replacement waned in view of the high morbidity and mortality? Observational data exist demonstrating that doing something in the downstream thoracic aorta, either with a surgical elephant trunk graft (as Dr Kazui advocated in patients with Marfan syndrome) or a stent graft, does not decrease the need for late reoperation nor increase survival. Has your approach changed on the basis of this analysis?

Dr Desai. I believe it was at the Southern Thoracic Surgical Association meeting this year that Dr Pochettino from our group presented our data on the hybrid type A repair, or so-called frozen elephant-trunk type A repair. Our initial belief is that this procedure has a future, that we have been able to show there is less dilatation of the proximal descending thoracic aorta. We have also shown it does increase the risk of paraplegia, which is not minor, and I think this is actually an ideal question to be answered with a randomized clinical trial, more so than almost any other group of patients who will undergo TEVAR.

Dr Miller. That is a good thought. For now, there is a substantial price the patient must pay to do so, both in terms of early death and paraplegia, and the rationale for doing so is based on a notion that is not proven.

What about the paraplegia risk? It really concerned me to hear you say that extent of descending thoracic aortic coverage (your term is extent $C$ coverage from the left subclavian artery to the diaphragm) has no apparent adverse effects or increases in the risk of spinal cord injury. When Frank Criado first published his results showing that the probability of spinal cord injury increases markedly as one covers more descending aorta with TEVAR, most surgeons promptly backed off, and I think patients benefited. But are you now telling me that with cerebrospinal fluid drainage and other adjuncts there no longer is an additive adverse risk? I am concerned about that, and I would urge all of us to be cautious, preserve whatever intercostal artery blood flow you can, and not get carried away with TEVAR covering excessive lengths of descending aorta. Please note that this admonition does not apply to using noncovered bare metal stents or the petticoat stent on a Cook TX2 dissection TEVAR system, which "paves" the distal true lumen down below the stent graft that has covered the primary intimal tear. We at Stanford like that distal adjunctive approach, but we really have to do everything we can to minimize the likelihood of spinal cord injury. Do you still think it is safe to cover large lengths of descending thoracic aorta?

Dr Desai. It has always been our approach to cover as little as necessary to get a seal, so in a type B dissection case, for instance, we do not aim to pave the whole aorta. We will try to cover the entry tear, reexpand the true lumen at the most proximal area, but not bring it all the way down to the celiac access except in cases of rupture. With aneurysm cases, again we try to ensure that we are in good landing zones for seal but not to cover more than that unless it is necessary. We do not recommend extending coverage because it is safe. What we are saying is that in our data set with the patients we operated on we did not see a difference. Now that may be because we have had a very proactive group of cardiac anesthetists and neurologists working with us who are involved in taking care of neurologic changes in the intensive care unit, which may not be the case in other centers. There is a complex interaction among patient-related factors, the original aortic pathology, revascularization of the subclavian when covered, and anatomic considerations, such as previous abdominal aortic aneurysm repair, that affect whether a patient has a postoperative problem with spinal cord ischemia. There are a lot of issues there, but in our data set with our approach we did not see a difference.

Dr Miller. How many times did you actively revascularize the left subclavian artery before, during, or after TEVAR?

Dr Desai. It varies by indication. In our current experience, any situation where we are going to cover the left subclavian electively we will bypass as a routine on any patient except in true emergencies.

Dr Miller. That is good to hear, and we strongly concur. Thanks for coming out to the 2009 Western Thoracic Surgical Association meeting in Alberta, Nimesh. 